\title{
Sinus Histiocytosis: An Uncommon Presentation of an Uncommon Condition
}

\author{
Allison Greco, MD \\ Thomas Jefferson University, allison.greco@jefferson.edu \\ Gregory Kane, MD \\ Thomas Jefferson University, gregory.kane@jefferson.edu
}

Follow this and additional works at: https://jdc.jefferson.edu/tmf

Part of the Medicine and Health Sciences Commons

Let us know how access to this document benefits you

\author{
Recommended Citation \\ Greco, MD, Allison and Kane, MD, Gregory (2015) "Sinus Histiocytosis: An Uncommon Presentation of an \\ Uncommon Condition," The Medicine Forum: Vol. 16, Article 15. \\ DOI: https://doi.org/10.29046/TMF.016.1.014 \\ Available at: https://jdc.jefferson.edu/tmf/vol16/iss1/15
}

This Article is brought to you for free and open access by the Jefferson Digital Commons. The Jefferson Digital Commons is a service of Thomas Jefferson University's Center for Teaching and Learning (CTL). The Commons is a showcase for Jefferson books and journals, peer-reviewed scholarly publications, unique historical collections from the University archives, and teaching tools. The Jefferson Digital Commons allows researchers and interested readers anywhere in the world to learn about and keep up to date with Jefferson scholarship. This article has been accepted for inclusion in The Medicine Forum by an authorized administrator of the Jefferson Digital Commons. For more information, please contact: JeffersonDigitalCommons@jefferson.edu. 


\section{Sinus Histiocytosis: An Uncommon Presentation of an Uncommon Condition}

Allison Greco, MD and Gregory Kane, MD

\section{INTRODUCTION}

Rosai-Dorfman Disease (RDD), also known as Sinus Histiocytosis with Massive Lymphadenopathy (SHML), is a rare, benign, proliferative disorder of macrophages and monocytes that was first described by Rosai and Dorfman in 1969. The vast majority of patients present with painless bilateral cervical lymphadenopathy during childhood or young adulthood. The condition is self-limited and rarely requires medical treatment. Involvement of extranodal sites such as eyelids, eye sockets, skin and subcutaneous tissue, gastrointestinal tract, upper airways and central nervous system have been infrequently described. Mediastinal involvement is extremely rare, and there are few cases reported in the literature.

Here, we present a case of a 61-year-old female with a history of mediastinal sinus histiocytosis with massive lymphadenopathy.

\section{CASE PRESENTATION:}

A 61-year-old female with history of hypercholesterolemia and vitamin D deficiency was referred to the Pulmonary clinic for evaluation of an abnormal chest radiograph which was concerning for a right-sided pleural effusion (Figure 1). The patient noted two to three weeks of increasing dyspnea on exertion, chest tenderness, a dry cough, and decreased exercise tolerance. She denied fevers, chills, night sweats, and weight loss. She reported a 10-pack-year smoking history, but denied other occupational exposures. There was no family history of pulmonary disease or malignancy. Vital signs were normal, and physical examination was notable only for decreased breath sounds in the lower one-third of the right lung and reproducible sternal tenderness.

Upon further review of her past medical history, the patient stated that she had similar symptoms several years ago and was subsequently noted to have an abnormal mass and lymph nodes near her esophagus in 2010. She underwent mediastinoscopy with biopsy of these nodes at that time, which was complicated by

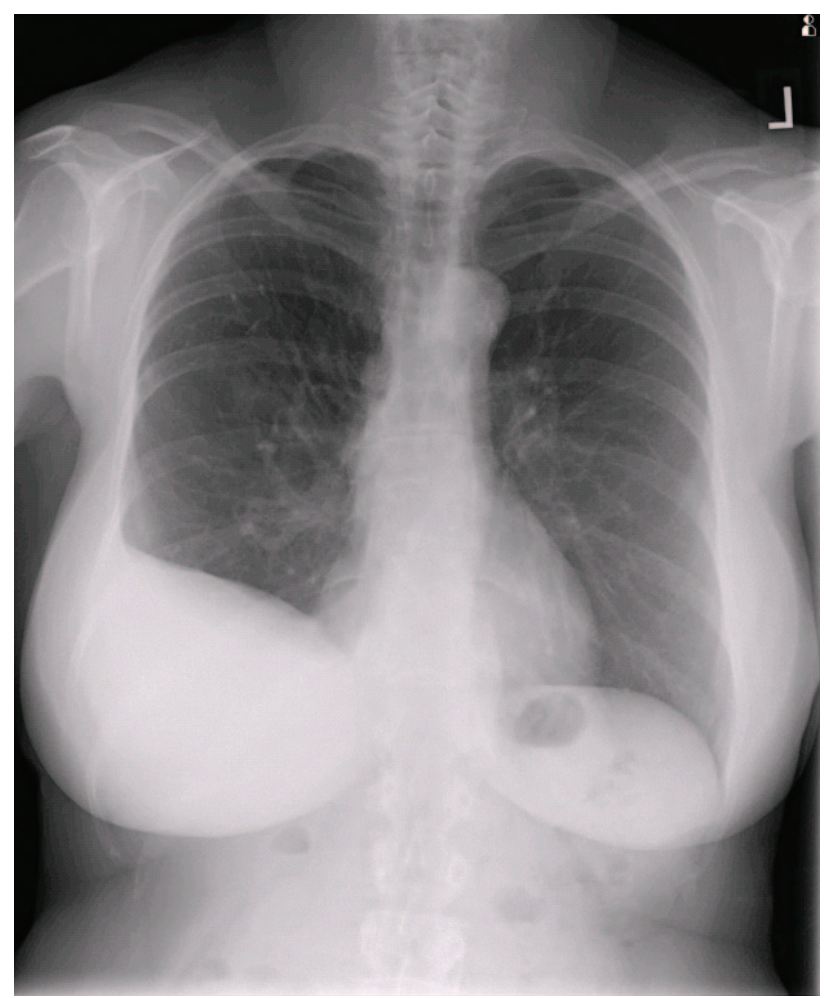

Figure 1. Plain chest radiograph at time of the patient's presentation depicting opacity at the right lung base concerning for pleural effusion.

esophageal perforation and emergent esophageal stent placement. She was told pathology at that time was benign and received limited follow up.

ACT of the thorax from initial presentation in 2010 revealed an abnormal $10 \mathrm{~cm}$, soft tissue mass in the subcarinal region (Figure 2A). There was a mild, right-sided pleural effusion with atelectasis in the right lower lobe. Nineteen biopsy specimens obtained during mediastinoscopy, including 19 excisional lymph node biopsies, were negative for malignancy and demonstrated pathology consistent with sinus histiocytosis with anthracosis. 

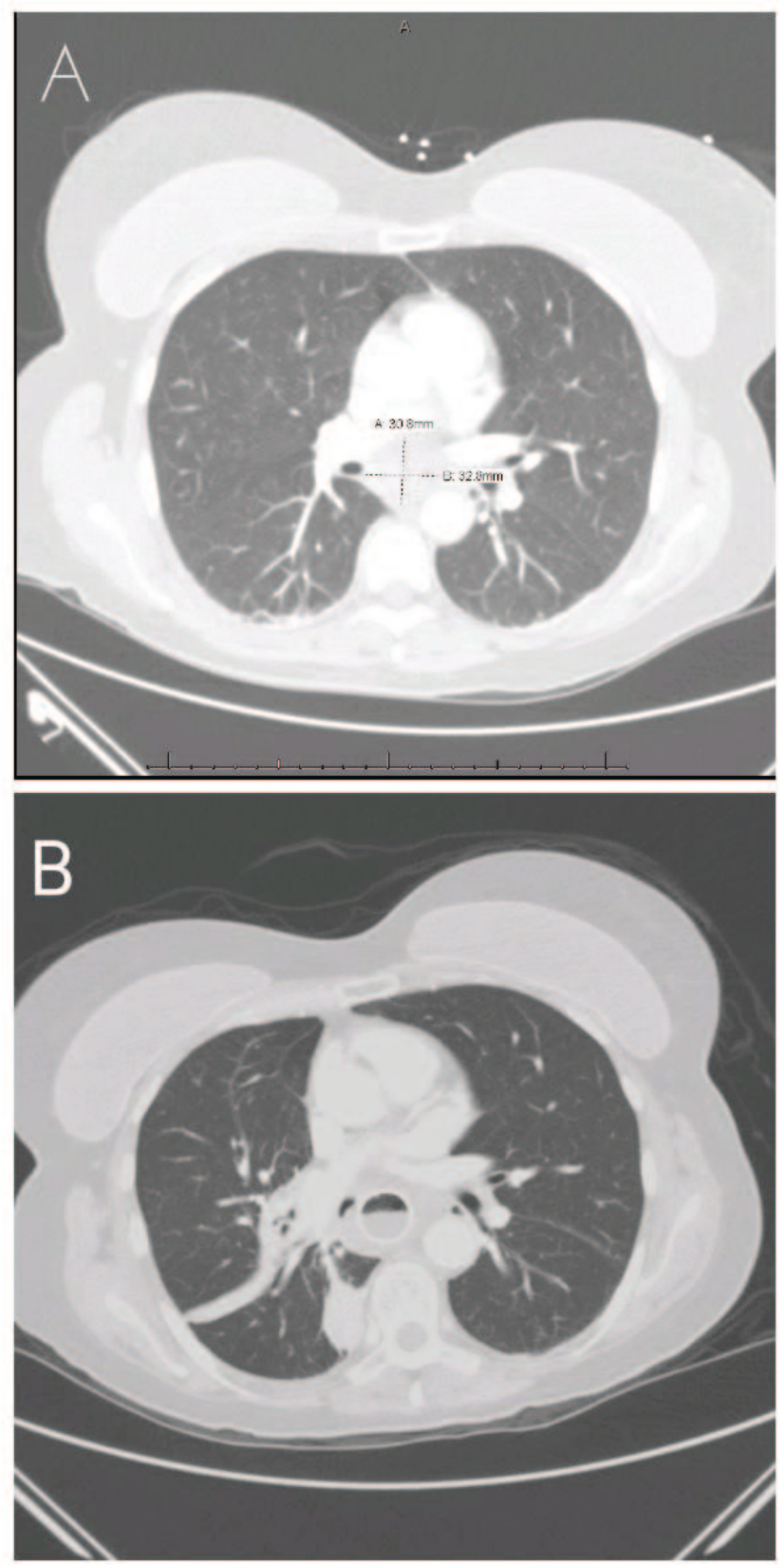

Figure 2. A CT scan of the thorax obtained in 2010 depicts a $30.8 x$ $32.8 \mathrm{~mm}$ mass concerning for malignancy (A). Biopsies of this mass obtained via mediastinoscopy revealed histology consistent with sinus histiocytosis. This procedure was complicated by esophageal perforation and esophageal stent placement, as pictured here (B)

Follow up imaging obtained after esophageal stent placement showed atelectasis in the right-lower lobe (Figure 2B)

Interestingly, a CT of the thorax from 2011 revealed complete resolution of the subcarinal mass, with persistent scarring in the right lower lobe (Figure 3).

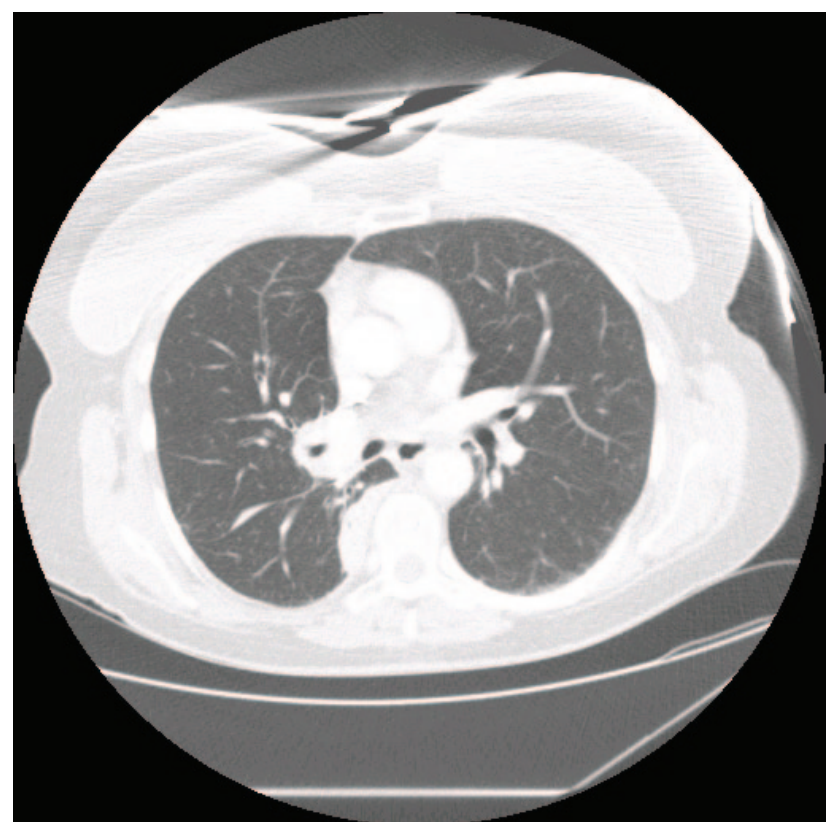

Figure 3. A CT of the thorax obtained in 2011 demonstrates interval removal of the esophageal stent, as well as resolving right lower love atelectasis and scarring. There is resolution of the subcarinal lymphadenopathy

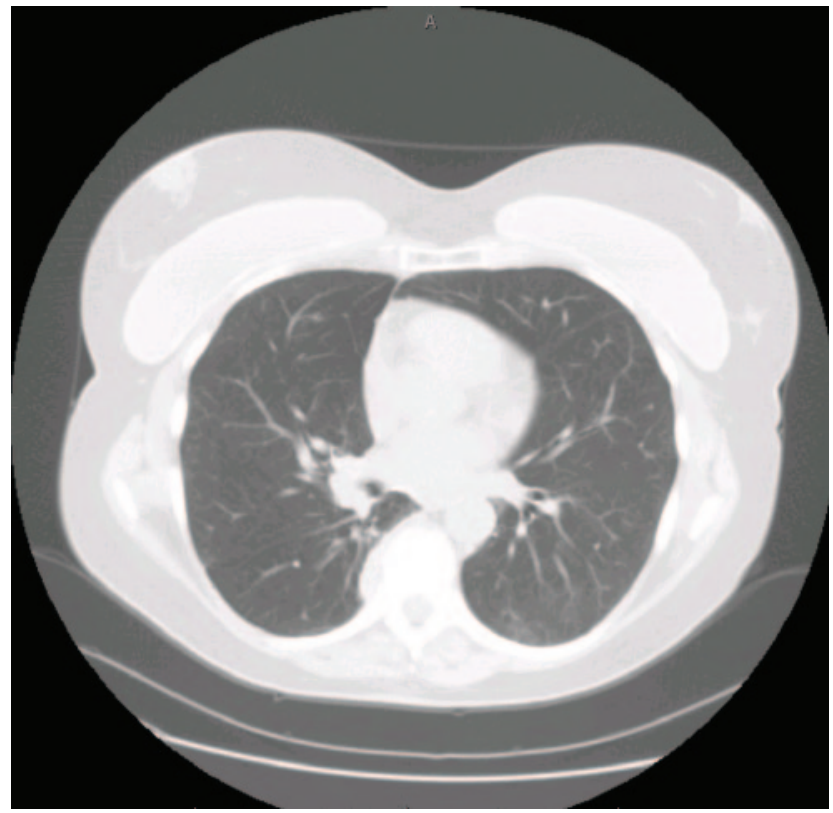

Figure 4. A non-contrast CT of the Thorax obtained in 2014 demonstrates resolution of the mediastinal mass as well as stable right lower lobe scarring without evidence of pleural effusion. These findings account for the right lower lobe opacity seen on plain chest radiograph (Fig. 1). 


\section{Greco, MD and Kane, MD: Sinus Histiocytosis}

\section{DIFFERENTIAL DIAGNOSIS:}

Differential diagnosis for the patient's radiographic findings at the time of current presentation included chylothorax given the patient's history of mediastinal instrumentation, malignancy, and persistence of sinus histiocytosis with lymphadenopathy. Additionally the presence of chest discomfort and shortness of breath indicated a possible cardiac etiology including valvular or ischemic heart disease.

\section{OUTCOME AND FOLLOW UP:}

Laboratory testing revealed normal metabolic panel, hepatic function panel, cell counts with differential, and inflammatory markers. An echocardiogram revealed normal left ventricular function without evidence of valvular disease or pulmonary hypertension.

A CT of the thorax revealed absence of consolidation, mass, and lymphadenopathy. There was no pleural effusion. There was an area of slightly improved scarring in the right lung base, accounting for the abnormal right lower lobe finding on plain chest radiography (Figure 4).

Pulmonary function testing revealed slight restrictive physiology with a decreased diffusion capacity that corrected when adjusted for volume loss caused by right lower lobe scarring.

Our hypothesis was that the patient suffered from Rosai Dorfmann disease in 2010 and that her biopsies and esophageal perforation caused the observed $x$-ray and CT findings that are stable to this current evaluation. As the patient's pulmonary workup was benign, she was encouraged to undergo further cardiac workup, including stress testing.

\section{DISCUSSION:}

Sinus histiocytosis with massive lymphadenopathy is primarily a benign proliferation of monocytes and macrophages that affects the cervical lymph nodes in children and young adults. Here we present a case of a 61-year-old female with mediastinal lymphadenopathy and histologic changes suggestive of SHML.

Review of the literature reveals several case reports of more typical SHML. Most patients not only present with painless, enlarged, cervical lymph nodes but may also have fever and an elevated erythrocyte sedimentation rate (ESR). Involvement of extranodal sites such as eyelids, eye sockets, skin and subcutaneous tissue, have been described. In the rare reported cases of mediastinal SMHL, patients may have pleural effusion or develop reactive or interstitial lung disease.

The presence of SHML can be identified histologically by the presence of large polyclonal histiocytes with abundant eosinophilic cytoplasm and infrequent mitoses. They generally demonstrate the expression of the S-100 protein.

While our patient's pathology did not specifically comment on the presence of the above histologic markers, perhaps the most notable factor that suggests the presence of SHML is the disease course; here we are able to examine serial imaging studies, which demonstrate complete resolution of massive mediastinal lymphadenopathy over the course of four years. A self-limited clinical course has previously been described, with the majority of patients receiving surgical debulking and systemic treatment with corticosteroids or chemotherapy only when organ systems become compromised.

\section{KEY POINTS:}

Sinus histiocytosis with massive lymphadenopathy is primarily a benign proliferation of monocytes in macrophages that typically affects the cervical lymph nodes in children and young adults. It typically involves a self-limiting clinical course that rarely requires treatment.

\section{REFERENCES}

1. Cartin-ceba R, Golbin JM, Yi ES, Prakash UB, Vassallo R, Intrathoracic manifestations of Rosai-Dorfman disease. Respir Med. 2010;104(9):1344-9.

2. Costa AL, Silva NO, Motta MP, Athanazio RA, Athanazio DA, Athanazio PR. Soft tissue Rosai-Dorfman disease of the posterior mediastinum. J Bras Pneumol. 2009;35(7):717-20.

3. Ju J, Kwon YS, Jo KJ, et al. Sinus histiocytosis with massive lymphadenopathy: a case report with pleural effusion and cervical lymphadenopathy. J Korean Med Sci. 2009:24(4):760-2

4. Mallick S, Ghosh R, Iyer VK, Jain D, Mathur SR. Cytomorphological and morphometric analysis of 22 cases of Rosai-Dorfman disease: a large series from a tertiary care centre. Acta Cytol. 2013;57(6):625-32

5. Ohori NP, Yu J, Landreneau RJ, Thaete FL, Kane K. Rosai-Dorfman disease of the pleura: a rare extranodal presentation. Hum Pathol. 2003:34(11):1210-1.

6. Ozlu T, Bulbul Y, Erol MM. A rare cause of mediastinal enlargement: sinus histiocytosis with massive lymphadenopathy. Arch Bronconeumol. 2011;47(3):161-2. 